(C) 1985 IEEE. Personal use of this material is permitted. However, permission to reprint/republish this material for advertising or promotional purposes or for creating new collective works for resale or redistribution to servers

or lists, or to reuse any copyrighted component of this work in other works must be obtained from the IEEE.

IEEE Transactions on Nuclear Science, Vol. NS-32. No. 5. October 1985

\title{
MATERIALS CONSIDERATIONS FOR A HIGH POWER-DENSITY ACCELERATOR*
}

R. A. Michelotti, R. A. Tennant, N. K. Bultman, J. I. Uher, R. J. Brewton, and Anton Mayer, AT-4, MS H821, $\checkmark$ Los Alamos National Laboratory, Los Alamos, NM 87545 USA

\section{Summary}

A $100-\mathrm{mA} 50-\mathrm{MeV} \mathrm{H} \mathrm{H}^{-}$accelerator is being designed at LoS Alamos. The accelerating structures will operate at $425-\mathrm{MHz}$ and will consist of a radio-frequency quadrupole (RFQ) to $2-M e V$ and a drift-tube linac (DTL) from 2 to $50-\mathrm{MeV}$. Design parameters have been speci fied to match the maximum operating capabilities of the rf system: 2-ms pulse length and $6 \%$ duty factor. The accelerating gradient in the DTL will be 4-MV/m; the maximum electric field will be approximately 1.2 times the Kilpatrick limit. These design parameters are substantially more ambitious than those of the accelerator test stand (ATS).

The larger accelerating gradient and increased duty factor will increase the average power density in the DTL to approximately 25 times the design values for the ATS DTL. The increased duty factor will raise the average power density on the proposed RFQ to approximately 6 times the operating values of the ATS RFQ. The instantaneous power density on the drift tubes is predicted to be $60 \mathrm{~W} / \mathrm{sq} \mathrm{cm}$, and the average power density is predicted to be $4 \mathrm{~W} / \mathrm{sq} \mathrm{cm}$. These power densities are not excessive, but do represent design challenges in specific areas. Some components where thermal difficulties may be encountered include RFQ vanes, drift tubes, post couplers, slug tuners, rf seals, and tuning bars.

That copper will be used on the rf-structure surfaces is not in question. Concern with residual activation and thermal management forces the investigation of materials other than the traditional carbon- and stainless-steel base materials used at Los Alamos. Physical constraints on cooling-channel design and a temperature limit on the permanent-magnet quadrupoles (PMQS) make the thermal management problem in the drfft tubes more complex. Beam spill and target shine from a high-energy high-average-current beam are serious concerns driving the component activation problem. Copper alloys and capper-plated aluminum are being investigated for suitability as alternatives to steels. Table I summarizes some of the relevant properties of potential copper and aluminum alloys.

TABLE I

PROPERTIES OF CANDIDATE MATERIALS

\begin{tabular}{|c|c|c|c|c|}
\hline & $\begin{array}{l}\text { Yield } \\
\text { (Time }\end{array}$ & $\begin{array}{l}\text { Strength } \\
5 \text { OFHC) }\end{array}$ & $\begin{array}{c}\text { Thermal } \\
\text { Conductivity }\end{array}$ & $\begin{array}{c}\text { Electrical } \\
\text { Conductivity }\end{array}$ \\
\hline CU Alloys & Hard ${ }^{a}$ & Softh & $(\%$ OFHC) & (\% IACS) \\
\hline $\begin{array}{l}\text { C18100 } \\
\text { C15000 }\end{array}$ & $\begin{array}{l}1.8 \\
1.4\end{array}$ & $\begin{array}{l}1.9 \\
1.2\end{array}$ & $\begin{array}{l}83 \\
94\end{array}$ & $\begin{array}{l}80 \\
93\end{array}$ \\
\hline
\end{tabular}

\section{A) Alloys}

$\begin{array}{lllll}6061 & 0.9 & 1.2 & 77 & 47 \\ 2219 & 1.3 & 1.1 & 66 & 44 \\ 5086 & 0.8 & 1.7 & 56 & 31\end{array}$

Reference - FuTl hard OFHC - 45000 psi ( $310 \mathrm{MPa}$ ).

beference - Dead soft OFHC - 10000 psi (69 MPa).

\footnotetext{
*Work supported by US Dept. of Defense and Ballistic Missile Defense Advanced Technology Center.
}

Qualitative criteria for the base material include the following items.

- Compatibility with a process for applying a smooth high-conductivity copper surface

- Moderate strength and hardness to ensure that components will not be damaged during normal handling operations

- High thermal conductivity and cooling-channel corrosion resistance for efficient heat removal

- Good mechanical and thermal stability to en sure that rf tuning is not compromised by dimensional changes

- Relative ease in fabrication, modification, or repair of components

- Residual activation that does not dominate over other components in the experimental area

- Material cost and availability

The temperature-limiting components of a OTL are probably the PMQs in the drift-tube bodies. The temperature of the PMQs cannot exceed $100^{\circ} \mathrm{C}$ without risk of permanently and detrimentally altering magnetic properties. Figure 1 illustrates the impact of material changes on PMQ temperature during operation; the cooling-channel configuration and coolant flow rate were based upon the ATS-OTL design. Because of the PMO temperature limit, a drift-tube-body material that has a high thermal conductivity will complicate the fabrication procedure.

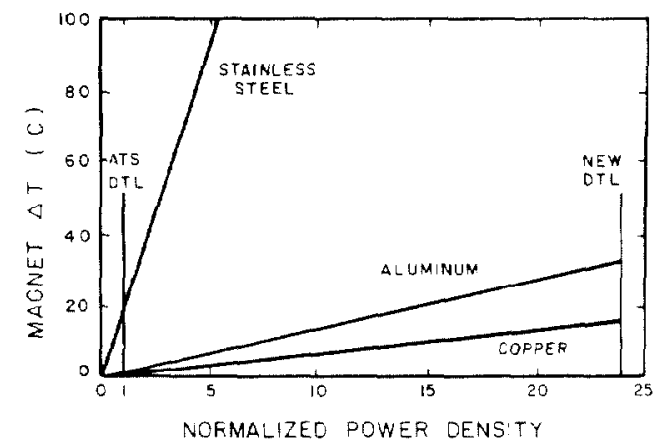

Fig. 1. Drift-tube-magnet temperature rise vs power density. Maximum allowable magnet temperature is $100^{\circ} \mathrm{C}$.

Prompt radiation and residual activation (within an 8-hr window) of copper-alloy components are substantially worse than for aluminum-alloy components. Figure 2 presents a comparison of the residual activation of aluminum and copper that is due to beam spill. A point source was assumed for radiation calculations.

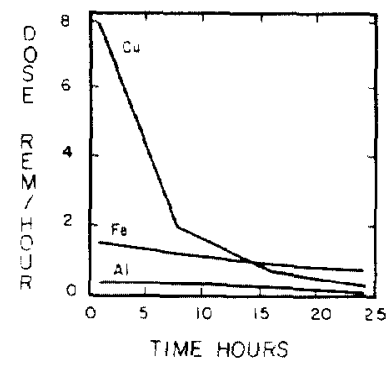

Fig. 2. Dose-equivalent rates at $1 \mathrm{~m}$ from the decay of activation products (a 50-uA time-averaged beam of 50 -MeV protons with beam-on time of $8 \mathrm{~h}$ ) (Fig. IV of Ref. 1.) 
Some copper alloys have a high enough electrical conductivity that copper plating may not be necessary. other copper alloys are relatively easy to plate. A copper-clad aluminum structure would provide an $\mathrm{rf}$ surface without the necessity of plating, but component fabrication would be severely complicated by the bimetallic joints. High-quality copper plating onto a large aluminum-alloy structure will require development, but the outlook is promising.

\section{Residual Activation}

Residual activation (within an 8-hr window) of accelerator components is a major issue in material selection. Based on residual activation properties. aluminum alloys are far more attractive than copper alloys or steei. Cooling requirements on specific components (such as drift tubes) make the use of highconductivity copper alloys attractive.

A thin graphite liner on the drift-tube bore is a concept for reducing beam-spill-induced component activation. ${ }^{2}$ If graphite layers can be applied to the bore tubes, some of the adverse activation effects of copper alloys may be mitigated. For the same reasons, graphite also is being considered for the beamstop surface as was planned for the 5-MeV Fusion Materials Irradiation Test (FMIT) accelerator. ${ }^{3}$ There are plans to evaiuate graphite-ta-copper bonding techniques using the 2-MeV FMIT accelerator. Residual activation of a graphite beamstop is shown in Fig. 3 .

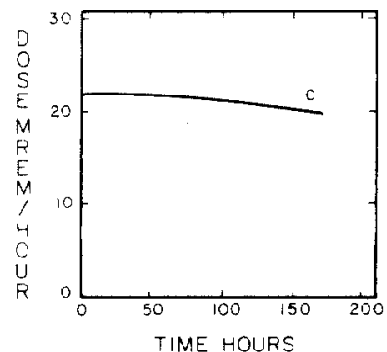

Fig. 3. Dose-equivalent rate at $1 \mathrm{~m}$ from the decay activation products a (1-mA time-averaged beam of $50-M e V$ protons on a carbon beamstop with beam-on time is $8 \mathrm{~h}$ ) (Fig. $V$ of Ref. 1.)

\section{$\underline{\text { Stee } 15}$}

Stainless and carbon steels traditionally have been used for accelerator structures, primarily because fabrication and plating techniques are well es tablished. The power densities of previous machines have been low enough to be compatible with the reldtively poor thermal conductivity of steels. Orift tubes are the components that are of highest concern. Carbon steels, and other magnetic materials, cannot be used on the drift-tube bores because of interference with magnetic focusing.

\section{Aluminum}

High-purity aluminum is soft and ductile, but gains strength and hardness when alloying elements are added. Some of the alloying elements used include copper, magnesium, silicon, manganese, and zinc. There are two categories of aluminum alloys: heattreatable alloys and work-hardened alloys. The $3 \times x \times$ and $5 \times x x$ series are work-hardened alloys, the $2 \times x x$, $6 \times x \times$, and $7 \times x x$ series are heat-treatable alloys. Both alloy types have good-to-excellent forming characteristics.

In most cases, fusion welding of the heattreatable aluminum alloys is not recommended. The problem can be described as high-temperature "hot" cracking of the weld and is characteristic of alloys with wide solidification ranges. High-strength characteristics of the base material cannot be obtained in the weld zone--even by posiweid heat treatment. Heavy-section welds, where joint restraint is inherent in the design, are very susceptible to hot cracking. The 6061 and 2219 alloys are heat treatable and have relatively good welding properties. 4,5

The work-hardened (non heat-treatable) alloys can be fusion welded by all conventional processes, including tungsten inert gas and electron beam. The strength of the welded region is considerably less than that of the parent metal. Of the 5000-series alloys, 5086 is one of the more desirable choices because of weldability and availability. The properties of 5086 are included in Table I. 4, 5

The 5000-series alloys have "as-welded" properties that are superior to those of 6061. Specifically, the as-welded yield strength is higher, and distortion and cracking are less severe.

\section{Copper ${ }^{6}$,}

OFHC copper is often used where high thermal and electrical conductivity, and vacuum compatibility are needed. Copper alloys are attractive alternatives to OFHC when an application also demands high strength, high recrystallization temperature, good cold-or hotworking properties, and machinability. Most copper alloys are readily machined by usual methods using standard tools designed for steel, operated at higher speeds. Because of the low recrystallization temperature and high thermal conductivity of copper alloys, most welding and brazing processes are not usable. Laser welding is expected to be marginal. E-beam welding appears to be the most attractive form of welding and will minimize changes in the strength and crystalline structure of a component.

Copper containing small amounts of silver retains the effect of cold working to a higher temperature than does OFHC (about $320^{\circ} \mathrm{C}$ compared with about $200^{\circ} \mathrm{C}$ ). This characteristic is useful where hightemperature operation is necessary and when hightemperature soldering or brazing is required. Tellurium and sulfur are added to enhance the machinability of copper with minimum sacrifice in conductivity. chromium and zirconium are added to increase strength and raise the recrystallization temperature, with little decrease in conductivity. Two particularly interesting alloys are chromium-zirconium copper (Copper No. C18100) and zirconium copper (Copper No. C15000). Table I includes a summary of their material properties.

\section{Corrosion}

Several factors should be considered to minimize corrosion problems in accelerator systems, including coolant type, coolant velocity, materials used, and fabrication techniques. If the coolant is water, additives and processing are necessary. From a general corrosion standpoint, aluminum alloys ( $1 \times x \times$ through $6 \times x x)$ witl behave essentially as pure aluminum. Copper alloys with at least $98 \%$ copper will behave as pure copper.

Aluminum alloys typically have a thin oxide film on exposed surfaces that makes them quasi stable in chloride- and sulfide free water between $\mathrm{pH} 6$ and 8 . When this film is damaged by chemical attack or coolant impingement, the surface will be eroded even in highly purified water. Conservative design limits of coolant flow velocities are $300 \mathrm{~cm} / \mathrm{s}$ for uniform flow and $60 \mathrm{~cm} / \mathrm{s}$ for impinging flow. Higher flow rates can be traded off against component lifetimes. 
Copper alloys remain stable with deionized water as the coolant. The deionizing and polishing system must remove sulfide and nitrogen compounds, and oxygen. A maximum corrosion rate of less than $0.7 \mathrm{~mm}$ per year can be achieved by maintaining the oxygen concentration below $0.1 \mathrm{ppm}$. Uther substances such as peroxide ions and radicals should be maintained below a total of $0.2 \mathrm{ppm}$ each. A conservative velocity limit for uniform flow is $500 \mathrm{~cm} / \mathrm{s}$ and $150 \mathrm{~cm} / \mathrm{s}$ for impinging flow.

Combinations of copper and aluminum can lead to galvanic attack of the aluminum. Particular locations where galvanic action is likely to be a problem include copper-plated aluminum and various type of lap joints that are in contact with water. Where such junctions are unavoidable, the aluminum component should be designed with increased thickness within $0.5 \mathrm{~cm}$ of the contact. Beyond that distance, the high-resistivity water will insulate electrolytic communication between the dissimilar metals. For systems that combine copper and aluminum, proper water chemistry is critical.

Joints of both similar and dissimilar metals in contact with flowing coolant can also produce a condition known as crevice corrosion. Crevice corrosion should not be a problem if deionized low-conductivity water is used and care is exercised in the design of lap or butt joints.

other general precautions should also be taken. The coolant should not be allowed to become stagnant. Even during beam shutdown, a reduced coolant flow rate should be maintained. Contact between the coolant and graphite, rust, or other particulate matter should be avoided. Ions and oxygen and other dissolved gases should be removed, especially in the coolant for the RFQ vanes and drift tubes.

\section{Copper Plating}

Surfaces exposed to $\mathrm{rf}$ are usualiy copper plated to minimize ohmic losses. Different plating processes are available, depending on the choice of base metal. Bright-acid copper plating has been used for rf structures at Los Alamos; it has a purity of greater than 99\% copper, but the oxygen content is not as low as for OFHC. Alkaline-plating processes, such as pyrophosphate- or cyanide-copper plating, may be attractive for an aluminum base.

The electrical conductivity of bright-acid plated samples has been measured to be $95 \%$ of the International Annealed-Copper Standard (IACS). Los Alamos has had experience with developing vendors for brightacid copper plating of large rf cavities on both the FMIT and ATS projects. These projects have used either carbon steel or stainless steel as the structural base. Copper plating onto a copper-allay structure is expected to be straightforward. Some alloys with high electrical conductivities may not need to be plated. A process and a vendor would have to be developed for plating bright-acid copper onto large aluminum structures.

Several activation processes are available to prepare aluminum for applying bright-acid copper plating:

1- zincate, cyanide-copper strike, bright-acid copper plate:

2- zincate, electroless nickel, nickel chloride strike, cyanide-copper strike, bright-acid copper plate:

3- Alstantm activation process, bright-acid copper plate.
Processes 1 and 2 were evaluated on 6061-T6 specimens at LoS Alamos; a single specimen of each process was used. Both specimens exhibited nonuniform grain structures and significant thickness variations. Adhesion was very poor for Process 2 but excellent for Process 1. An outgassing measurement is planned but has not yet been performed.

zinc is normally a "forbidden" material in vacuum systems, but the quantities of zinc involved in Processes 1 and 2 probably are low enough that they do not present a problem. The Alstan process does not use an intermediate zinc layer; it is not widely used for structural components--therefore, it is at an earlier stage in development than Processes 1 and 2 . Development of a process and a vendor will be necessary, regardless of which process is chosen.

\section{Conclusion}

Based on a preliminary investigation, both aluminum and copper alloys appear to be viable candidates as the base material for accelerator components in high power-density applications. It is very likely that different materials will be chosen for different components. With some development of copper plating onto large aluminum structures, we expect that aluminum alloys will be suitable for a majority of accelerator components. The issue of residual activation is severe, but can be managed with the combined use of aluminum, graphite coatings, and restricted accelerator access.

\section{References}

1. W. B. Wilson, E. D. Arthur, "Dose-Equivalent Rates From the Decay of Activation Products From Proton Irradiation of Copper. Aluminum Alloys and Carbon," to D. Schneider, T. Cole, Los Alamos National Laboratory memorandum $T-2-M-1540$, September $28,1984$.

2. J. Ungrin, CRNL. Personal commication.

3 D. Liska, L. Carlisle, F. Sigler, J. McCormick, D. Greenwood, R. Grieggs, J. Uher, G. Zimmerman. "Mechanical Design of the High-Energy BeamTransport Line for the FMIT 2-MeV Accelerator," IEEE Trans. Nuc 1. Sci. 30 (4) (1983), 2824.

4. H. Casey, J. J. Dvorak, "Selection and Avallability of Wrought Aluminum Alloys for Miscellaneous LASL Applications," Los Alamos Scientific Laboratory, CMB-6 Fabrication Section Memorandum No. 692, February 25, 1976.

5. W. C. Turner, "Your Memo or February 25, 1976 on Aluminum Alloys," to J. Ovorak, H. Casey, Los Alamos Scientific Laboratory memorandum Q-23, April 7, 1976.

6. T. Baumeister, E. A. Avalion, T. Baumeister III, Eds: Mark's handbook for Mechanical Engineers. Eighth Edition. (McGraw-Hill Book Co., New York, 1978) Chap. 6, 59-71, 75-81.

7. "AMAX-MZC," Interim Publication, AMAX Copper Inc., New York. NY.

8. G. E. Stoner, University of Virginia. Personal Communication.

9. A. Mayer, J. L. Uher, W. A, Wright, "Electroplating of Radio-Frequency Quadrupole Accelerator Components, "Plating and Surface Finishing, October 1983. 